\title{
APRESENTAÇÃO \\ Catástrofes, crises e respostas políticas e sociais
}

\section{PRESENTATION}

Disasters, crises and political and social responses

José Damião Rodrigues ${ }^{1}$ 
Resumo: Aolongo dos séculos, as sociedades humanas buscaram entender e explicar as manifestações violentas da natureza que se abatiam sobre elas sob as mais diversas formas (secas, chuvas intensas e tempestades, inundações, sismos, erupções, pragas, epidemias). Durante muito tempo, também, as explicações fornecidas estiveram integradas em cosmologias ou narrativas que correspondiam a tipos de crenças mágicas ou religiosas que, ao mesmo tempo que davam um sentido ao cosmos e procuravam aliviar a ansiedade das sociedades antigas face à sua vulnerabilidade, legitimavam uma determinada ordem política e social. Um dos tópicos que mais se evidencia na investigação conduzida neste âmbito é o das catástrofes naturais. Não se trata de pensar a história como catástrofe, como a entendia Walter Benjamin, mas de observar as catástrofes enquanto um "facto social total" (Marcel Mauss), na medida em que a sua ocorrência e os respetivos impactos afetam múltiplas dimensões das sociedades atingidas, revelando das mesmas aspectos que, em condições de normalidade, poderiam passar despercebidos. Palavras-chave: catástrofes naturais; clima; crises; história das catástrofes.

Abstract: Over the centuries, human societies have sought to understand and to explain the violent manifestations of nature that hit them in the most diverse forms (droughts, intense rains and storms, floods, earthquakes, eruptions, plagues, epidemics). For a long time, too, the explanations provided were integrated into cosmologies or narratives that corresponded to types of magical or religious beliefs that, while giving a sense to the cosmos and seeking to alleviate the anxiety of ancient societies in the face of their vulnerability, legitimized a certain political and social order. One of the topics that is most evident in the research conducted in this area is that of natural disasters. It is not a matter of thinking about history as a catastrophe, as Walter Benjamin understood it, but of observing catastrophes as a "total social fact” (Marcel Mauss), insofar as their occurrence 
and the respective impacts affect multiple dimensions of the affected societies, revealing certain aspects that, under normal conditions, could go unnoticed.

Keywords: natural disasters; climate; crisis; history of natural disasters. 
Ao longo dos séculos, as sociedades humanas buscaram entender e explicar as manifestações violentas da natureza que se abatiam sobre elas sob as mais diversas formas (secas, chuvas intensas e tempestades, inundações, sismos, erupções, pragas, epidemias). Durante muito tempo, também, as explicações fornecidas estiveram integradas em cosmologias ou narrativas que correspondiam a tipos de crenças mágicas ou religiosas que, ao mesmo tempo que davam um sentido ao cosmos e procuravam aliviar a ansiedade das sociedades antigas face à sua vulnerabilidade, legitimavam uma determinada ordem política e social.

No Ocidente europeu, foi sobretudo a partir do período renascentista que se assistiu ao emergir de novos discursos acerca da origem dos fenómenos naturais, ainda que a narrativa dominante permanecesse associada a visões religiosas ou mágicas - para não dizer supersticiosas: basta pensar na multiplicação de interpretações negativas, associadas ao Diabo, dos flagelos naturais e no número de processos por feitiçaria (HILDESHEIMER, 1990; MANDROU, 1968) - do mundo e também ao aumento de registos relativos à ocorrência desses mesmos fenómenos. A este respeito, importa saber se o crescimento verificado em relação aos registos correspondeu a uma efectiva maior frequência dos mesmos - pensemos, por exemplo, nos efeitos da Pequena Idade do Gelo, que alguns textos deste dossiê focarão -, a uma maior curiosidade pré-científica ou a um eventual uso político desse tipo de manifestações. Em suma, trata-se de uma questão heurística de crítica das fontes e da sua colocação em contexto, sendo certo que a sua distribuição é bastante assimétrica.

$\mathrm{Na}$ viragem do século XVIII para o século XIX, com a emergência das ciências modernas, as chamadas ciências naturais, mas também as ciências sociais e humanas, uma interpretação científica da natureza afirmou-se progressivamente, por entre novas formulações e hipóteses, sucessivamente submetidas a crítica e revistas, e o aprofundamento da investigação, sustentada em investigação e trabalho de campo. No campo das ciências sociais e humanas, embora a análise dos processos e dinâmicas societais estivesse por vezes presente como pano de fundo dos eventos descritos, os fenómenos naturais não ocupavam o primeiro plano. No caso da história, a constituição de um território historiográfico associado à história do clima ou à climatologia histórica, à história ambiental e, por fim, à história das catástrofes pode encontrar-se nas décadas finais do século XX.

Um marco indiscutível no nascimento deste novo território historiográfico foi a publicação do agora célebre livro do historiador francês Emmanuel Le Roy 
Ladurie, Histoire du climat depuis l'an Mil (LE ROY LADURIE, 1967). Nesta obra pioneira, o autor mostrou que era possível fazer-se uma história do clima, com base em múltiplas fontes, examinadas de forma meticulosa, visando conhecer o clima do passado, identificar as respostas das autoridades e dos grupos sociais às situações de crise e assinalar os períodos de alterações climáticas e as suas consequências à escala das sociedades. Não obstante a inovação contida na proposta teórica e metodológica de Emmanuel Le Roy Ladurie, este eixo historiográfico não foi seguido nos anos seguintes. Apenas em anos mais recentes se consolidou uma climatologia histórica, disciplina jovem, conforme notou Mariano Barriendos, e cuja entrada em cena se deve à constatação de que as sociedades contemporâneas enfrentam um problema grave à escala global com o aquecimento global e os seus efeitos nefastos (BARRIENDOS, 2011). É pois neste contexto historiográfico que surgem cada vez mais estudos e projectos (MASSARD-GUILBAUD, 2010), também em Portugal² e em Espanha, sendo o dossiê que agora apresentamos uma modesta introdução a um desses projectos, esperando que possa estimular o interesse de jovens historiadores por uma área em pleno desenvolvimento.

Um dos tópicos que mais se evidencia na investigação conduzida neste âmbito é o das catástrofes naturais. Não se trata de pensar a história como catástrofe, como a entendia Walter Benjamin, mas de observar as catástrofes enquanto um "facto social total” (Marcel Mauss), na medida em que a sua ocorrência e os respectivos impactos afectam múltiplas dimensões das sociedades atingidas, revelando das mesmas aspectos que, em condições de normalidade, poderiam passar despercebidos. Neste sentido, a catástrofe é um construto social, um conceito operatório que orienta a análise dos cientistas sociais, no caso presente dos historiadores (OLIVEIRA, 2019; SÉGUY et al., 2009).

A partir do Departamento de História Moderna daUniversidade de Alicante,em Espanha, Armando Alberola Romá e os seus mais directos colaboradores, entre os quais se conta o professor da mesma instituição Cayetano Mas Galvañ e ainda Adrián García Torres, deu início a uma linha de pesquisa que tinha como foco estudar o impacto de catástrofes de origem atmosférica ou hidrometeorológica, geológica ou biológica nas sociedades e economias da Idade Moderna, sendo de sublinhar que o período estudado englobava a oscilação climatérica conhecida como a Pequena Idade do Gelo, que tem merecido a atenção de diversos historiadores (ALBEROLA, 2014; BLOM, 2019; THE LITTLE..., 2014). A partir de Espanha e da região de Alicante, através de sucessivos estudos e projectos, Armando Alberola Romá e a sua equipa alargaram a sua perspectiva e o resultado 
de décadas de porfiada investigação materializou-se em artigos e livros que congregam os resultados de colaborações uniram os espaços mediterrânicos e os iberoamericanos. É uma síntese deste percurso, com ênfase no projecto em curso, Clima, riesgo, catástrofe y crisis a ambos lados del Atlántico durante la Pequeña Edad del Hielo (PEH) (2018-2021), que nos é apresentada no artigo assinado por Armando Alberola Romá e Cayetano Mas Galvañ neste dossiê.

No texto seguinte, Adrián García Torres, que iniciou a sua formação na Universidade de Alicante, transporta-nos até ao Equador setecentista, analisando os ciclos eruptivos do vulcão Cotopaxi (1742-1744 e 1766-1768) e do vulcão Tungurahua (1773-1781), este menos devastador do que a erupção do Cotopaxi em 1768. O seu propósito, além de identificar os impactos socioeconómicos causados, passa por destacar as políticas de emergência e de gestão de catástrofes com que as autoridades bourbónicas responderam aos efeitos catastróficos das erupções. O autor apoiou-se para tal em inúmeras fontes arquivísticas - Archivo General de Indias, Archivo General de la Nación de Colombia, Archivo Nacional del Ecuador e Archivo Histórico Nacional (Espanha) - e outra documentação coeva. De entre as conclusões, o autor ressalta que as políticas adoptadas pela administração imperial espanhola nestes casos não foram, em geral, diferentes das respostas dirigidas a outros desastres naturais.

Por fim, com María Eugenia Petit-Breuilh Sepúlveda, damos um salto no tempo e no espaço para nos situarmos na cidade chilena de Valparaíso, vítima de mais um terramoto no dia 16 de Agosto de 1906, causador de um elevado número de mortos e de avultados danos materiais, agravados pelo incêndio que se seguiu ao sismo. No seu artigo, a autora explora a gestão da catástrofe, nomeadamente a acção dos serviços sanitários (hospitais, postos de socorro) e a participação de funcionários, militares e civis na tentativa de apoiarem os mais necessitados e ajudar a cidade a recuperar da devastação. Utiliza fontes da época, como relatórios, e nas suas conclusões adianta que não se pode atribuir unicamente ao terramoto de 1906 a perda de importância de Valparaíso, sendo de equacionar também a abertura do Canal do Panamá ou a vitalidade industrial de Santiago de Chile. Por outro lado, entre as consequências socioeconómicas do sismo, aponta a diminuição do fosso entre os mais ricos e os mais pobres da cidade.

Em conclusão, com este pequeno, mas, cremos, sugestivo dossiê, pretendemos chamar a atenção para um território historiográfico de elevado potencial de inovação, não apenas pelos dados concretos relativos a cada desastre natural, 
mas também pelo facto de possibilitar a realização de estudos comparativos e na longa duração em várias regiões da América Latina e da Europa. De igual modo, o estudo da gestão do risco e das respostas das autoridades aos impactos das catástrofes colocam-nos perante o início de políticas públicas que permite avaliar o fluxo da comunicação política entre centros e periferias e a articulação entre as escalas, local, regional, nacional e global.

\section{Referências}

ALBEROLA, Armando. Los cambios climáticos. La Pequeña Edad del Hielo en España. Madrid. Ediciones Cátedra, 2014.

BARRIENDOS, Mariano. La climatologie historique: aspects méthodologiques. Sa contribution à la reconstruction climatique. In: CLÉMENT, François (dir.). Histoire et nature: pour une histoire écologique des sociétés méditerranéennes (Antiquité et Moyen-Âge). Rennes: Presses universitaires de Rennes, 2011, p. 2329. doi.org/10.4000/books.pur.112691.

BLOM, Philipp. Nature's Mutiny: How the Little Ice Age of the long seventeenth century transformed the West and shaped the present. New York: Liveright Publishing, 2019.

HILDESHEIMER, Françoise. La terreur et la pitié: L'ancien régime à l'épreuve de la peste. Paris: Publisud, 1990.

LE ROY LADURIE, Emmanuel. Histoire du climat depuis l'an Mil. Paris: Flammarion, 1967.

MANDROU, Robert. Magistrats et sorciers en France au XVII siècle: une analyse de psychologie historique. Paris: Plon, 1968.

MASSARD-GUILBAUD, Geneviève. Bilan historiographique de l'histoire environnementale. 2010. Disponível em: https://ahcesr.hypotheses.org/ files/2016/04/AHCESR-hist-environnementale.pdf.

OLIVEIRA, Eliézer Cardoso de. Quando as tragédias explicam: a importância heurística das catástrofes para o conhecimento histórico. História: Debates e Tendências, Passo Fundo, v. 19, n. 1, , p. 147-157, jan./abr. 2019.

SÉGUY, Isabelle et al. Vers une anthropologie des catastrophes. Paris: INED, 2009. THE LITTLE ice age: climate and history reconsidered. The Journal of 
Interdisciplinary History, Cambridge, v. 44, n.3, p. 299-300, 2014.

\section{Notas}

${ }^{1}$ Faculdade de Letras da Universidade de Lisboa/Centro de História da Universidade de Lisboa (ULisboa).

${ }^{2}$ Sirva de exemplo o projecto Dunes - Sea, Sand, People / O Mar, a Areia e as Gentes. Uma História Ambiental das Dunas Costeiras, coordenado por Joana Gaspar de Freitas no âmbito do Centro de História da Universidade de Lisboa [URL: <http://dunes.letras. ulisboa.pt>]. 